Citation: I. Melgarejo-Moreno (2021) Dimensiones e indicadores de la competencia mediática en Educación Infantil. Media Education 12(1): 67-78. doi: 10.36253/me-10269

Received: December, 2020

Accepted: April, 2021

Published: May, 2021

Copyright: @ 2021 I. Melgarejo-Moreno. This is an open access, peer-reviewed article published by Firenze University Press (http://www.fupress.com/me) and distributed under the terms of the Creative Commons Attribution License, which permits unrestricted use, distribution, and reproduction in any medium, provided the original author and source are credited.

Data Availability Statement: All relevant data are within the paper and its Supporting Information files.

Competing Interests: The Author(s) declare(s) no conflict of interest.

\section{Dimensiones e indicadores de la competencia mediática en Educación Infantil}

\section{Dimensions and indicators of media literacy in Pre-school Education}

\author{
Irene Melgarejo-Moreno \\ UCAM Universidad Católica de Murcia \\ E-mail: imelgarejo@ucam.edu
}

\begin{abstract}
Media literacy is based on dimensions that include a series of indicators that address knowledge, skills and attitudes of the so-called media competence. The purpose of this study is to facilitate the promotion of media competence in the Second Cycle of Early Childhood Education, for which it is necessary to carry out a selection and adaptation of the dimensions and indicators in relation to the characteristics of the child, which facilitate its implementation in the classroom by teachers and the progressive acquisition of this competence in students. An exhaustive review of the literature on media literacy and in relation to the nature of childhood is carried out in order to adapt the indicators to the particularities of this educational stage.
\end{abstract}

Keywords: educommunication, childhood, media literacy, pre-school education, teacher training.

Resumen. La alfabetización mediática se fundamenta en unas dimensiones que comportan una serie de indicadores que atienden a conocimientos, destrezas y actitudes de la denominada competencia mediática. El propósito de este estudio es el de facilitar el fomento de la competencia mediática en el Segundo Ciclo de Educación Infantil, para lo que se hace necesario llevar a cabo una selección y adaptación de las dimensiones e indicadores en relación a las características del niño, que faciliten su implementación en las aulas por parte del profesorado y la adquisición progresiva de esta competencia en el alumnado. Se realiza una revisión exhaustiva de la literatura en materia de alfabetización mediática y en relación a la naturaleza propia de la infancia con el fin de adecuar los indicadores a las particularidades propias de esta etapa educativa.

Palabras clave: competencia mediática, educación infantil, educomunicación, formación del profesorado, infancia.

\section{EL NIÑO DE 3 A 6 AÑOS: DESARROLLO Y CARACTERÍSTICAS}

La infancia ocupa una amplia parcela del desarrollo psicológico, cognitivo y físico de todo ser humano que va desde los 0 hasta aproximadamen- 
te los 10 años de edad. Durante todo ese transcurso de tiempo, los cambios tanto en lo físico como en lo intelectual son notables, pues en cada una de las etapas del desarrollo el niño ha ido conformando su personalidad dentro de la sociedad. Para formarse como persona, en él han influido muchos factores externos cercanos a su entorno como la familia, la escuela, los amigos, así como la relación con los medios de comunicación, entre otros muchos factores que convergen entre sí para la formación del menor. En este sentido, no podemos perder de vista en este proceso a la denominada Inteligencia Fílmica que permite conocer las características específicas que presenta el niño en cada una de sus etapas a la hora de enfrentarse a los productos audiovisuales, en concreto en la de 3 a 6 años que son los sujetos que abarcan este estudio. Con el desarrollo de la Inteligencia Fílmica se pone de manifiesto aquel proceso del desarrollo psicológico y cognitivo del menor por el que éste es capaz de asimilar y entender de forma óptima lo que los medios de comunicación le quieren transmitir o enseñar a través de sus mensajes. Este desarrollo va unido a las etapas de la evolución social, cognitiva, física y psicomotora del niño, pues como afirma De Andrés (2006) es necesario todo un proceso de asimilación audiovisual que culmine en la inteligencia fílmica para que los medios de comunicación, como puede ser el cine o la televisión, cumplan una función favorable dentro del entorno social y afectivo del menor.

En esta etapa que nos ocupa, de los 3 a los 6 años, el menor comienza a percibir la realidad a través de las distintas operaciones del pensamiento que va adquiriendo a través de su propio desarrollo físico y psicológico (Katz, Busemann, Piaget \& Inhelder, 1985). Como afirma De Andrés: "La percepción audiovisual es (...) una vivencia polisensorial de carácter evolutivo en la que se ha de valorar la maduración progresiva de los sistemas sensoriales comprometidos como la importancia de la estimulación y del aprendizaje" (2006, p. 45). Por tanto, a partir de los 3 años se producen los primeros pasos hacia la consecución de una plena inteligencia fílmica y es entonces cuando los mensajes audiovisuales comienzan a cobrar significación e importancia en las formas de actuación del niño. Aspectos como la estructura narrativa, los personajes infantiles y el antropomorfismo, las emociones, los valores y los contravalores, lo lúdico, la imitación, la confusión entre realidad y ficción, el lenguaje o la duración, se tienen en cuenta en el proceso madurativo audiovisual del menor.

A grandes rasgos, este periodo de los 3 a los 6 años se caracteriza por las funciones del conocimiento, la representación y la afectividad (Katz, Busemann, Piaget e Inhelder, 1985) que le ayudan a conformarse como

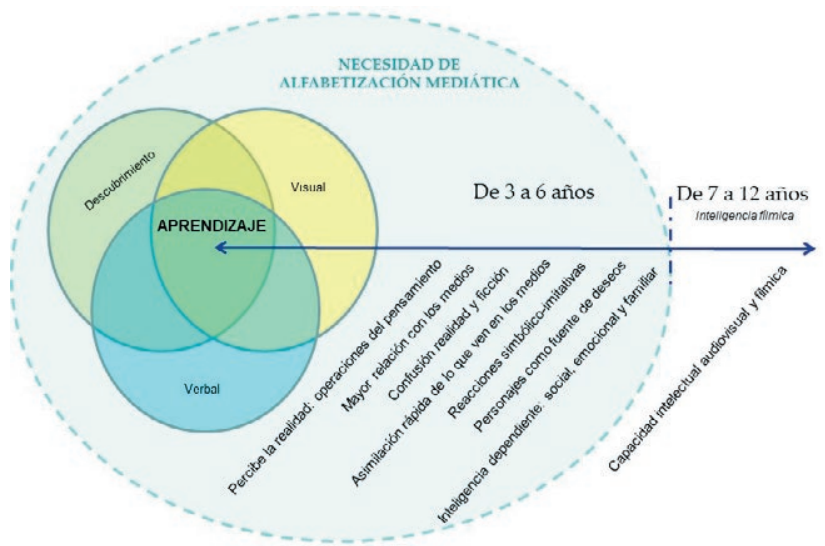

Figura 1. Primeros pasos hacia la Inteligencia Fílmica. Fuente: elaboración propia.

persona y a conocer la estructura de la sociedad, a veces transmitida por los medios de comunicación. Pese a ello, es evidente que, a esta edad, el niño no está formado en aspectos relacionados con la educomunicación, de ahí que en los estudios se destaquen aspectos sobre sus gustos o la descripción del producto, pero sin conseguir dar una argumentación sobre la producción audiovisual que decide o no ver y en consecuencia sobre su mensaje. De ahí la importancia de un buen proceso de enseñanza aprendizaje en esta materia, sin perder de vista las características fundamentales de la percepción audiovisual y el aprendizaje por descubrimiento (conectar las actividades, simular la realidad y participar de las actividades), el visual (mostrar actividades, demostraciones y visuales) y el verbal (escuchar y leer) que acompañarán todo el desarrollo del individuo. En este sentido, hasta los 6 años de edad podemos caracterizar a esta etapa en base a la comprensión audiovisual atendiendo a las características propias del desarrollo de la inteligencia fílmica que quedan resumidas en el siguiente gráfico (Figura 1).

\section{LA COMPETENCIA MEDIÁTICA COMO SIGNO DE CALIDAD EN EDUCACIÓN INFANTIL}

Los menores pasan gran parte de su tiempo (5 horas diarias) frente a las pantallas, como muestran los estudios de 2018 y 2019 de la Asociación para la Investigación de Medios de Comunicación (AIMC), combinando tecnología tradicional con la de nueva generación. De hecho, autores como Jiménez-Morales, Montaña, Medina-Bravo abogan por la necesidad de "evaluar el impacto de la tecnología en su bienestar y el grado de alfabetización digital" (2020, p.22). Debemos ser conscientes que los niños de 0 a 6 años consumen diversos medios (tele- 
visión, radio, cine, internet) y en ellos se encuentran un lenguaje para el que no han sido educados; un lenguaje audiovisual que podría presentarse como desconocido, pero que son capaces de comprender y no así de consumir de forma adecuada, responsable y crítica. Debemos pensar en que la realidad que presentan algunos medios puede estar alterada, distorsionada y diferir, en gran medida, de lo que es real y los más pequeños, a estas edades, no disponen de los conocimientos necesarios para hacer frente a la avalancha de información. Pero ¿cómo hacer frente a ella si las familias, las instituciones públicas y los propios medios no fomentan una alfabetización mediática?, la única solución que se vislumbra más eficaz es la intervención desde la escuela, donde ya encontramos una competencia digital que abarca algunas cuestiones relacionadas con este tipo de alfabetización, bien o mal desarrollada en las aulas de Educación Infantil (E.I.), pero que por lo menos ya consta en los documentos oficiales como es el currículum en los que se deja patente la importancia de los medios audiovisuales en el desarrollo de la infancia. Por este motivo, los medios no pueden ser estudiados como un contenido aislado, ni como simplemente un recurso al servicio de otras disciplinas, sino que debemos atender a la globalidad de los mismos dentro del sistema de enseñanza en estas edades tan tempranas. Buscando que sean una guía dentro de su mundo infantil mediatizado.

El lenguaje audiovisual no es algo nuevo, nos acompaña desde hace décadas, sin embargo, el ámbito educativo casi nunca se ha parado a pensar en la importancia de saber leer este tipo de lenguaje. Es en el siglo XXI cuando nos encontramos con una sociedad no alfabetizada mediáticamente, lo que abre una gran brecha digital generacional en todos los ámbitos sociales (familiar, laboral, educativo). Por tanto, consideramos que la calidad educativa debe pasar también por el trabajo exhaustivo y adecuado de la competencia mediática en las aulas, lo que implica el conocimiento de los diferentes elementos que conforman el lenguaje audiovisual desde los aspectos más fundamentales de este tipo de comunicación (bloques, tipografía de planos, continuidad, etc.) hasta aquellos elementos que hacen referencia a las narrativas audiovisuales (creación del relato, criterios narrativos, nuevas formas, etc.) y para ello, se hace necesaria una formación del profesorado en esta materia. Podríamos considerar que uno de los motivos por los que la educación puede que peque de baja calidad en España es por el trabajo inadecuado de alguna de las competencias, como la digital y la mediática, a la que apenas se le ha dado importancia, mientras en otros países se pueden encontrar experiencias educativas (Kotilainen y Kupianen, 2015; Eleá, 2014; Erstad, Miño \& Rive-
ra-Vargas, 2021) donde se trabaja tanto transversal como de forma específica aportando sentido y sobre todo, despertando en los alumnos aspectos como la creatividad, la consciencia ciudadana, la consciencia intercultural, la comprensión y el pensamiento crítico desde los primeros años escolares. El problema parece radicar en la introducción de esta competencia mediática en el entorno educativo, cómo abordarlo, en qué aspectos debe formarse el docente, qué habilidades se han de fomentar en el niño, a quién corresponde la responsabilidad de alfabetizar mediáticamente... un sinfín de incógnitas que, a pesar de haber sido abordadas por distintas instituciones, no se han visto materializadas, mientras los medios siguen su evolución en un mundo globalizado con una sociedad cada vez más hipercomunicada en la que hay que redefinir la educación teniendo en cuenta la comunicación y el lenguaje tecnológico (Gozálvez, 2012). Se trata de "revisar aspectos y contenidos curriculares, la metodología docente, los modos de evaluación, entre otras cosas para abrir sus puertas a la afectividad, a la nueva sensibilidad social en un nuevo entorno tecnológico y laboral en constante renovación" (Gozálvez, 2012, p. 152). Por tanto, en las próximas líneas trataremos la necesidad de adaptación que requieren las dimensiones y los indicadores de la competencia mediática para poder ser trabajados en la E.I. Este hecho, facilitaría en gran medida su implementación por parte de los docentes con alumnos que se encuentren en esta etapa educativa.

\section{METODOLOGÍA}

Llevar a cabo una adaptación de las dimensiones e indicadores de la competencia mediática requiere el acercamiento a las características del alumnado del Segundo ciclo de E.I. y, por lo tanto, a la naturaleza propia del infante. De esta forma, se plantea una metodología en la que no se pierden de vista las dimensiones originarias y generales marcadas por los teóricos fundamentales en la materia, las características cognitivas y psicológicas que marcan el desarrollo del niño en esta etapa y los conocimientos sobre competencia mediática que de partida tienen los maestros de esta etapa educativa.

Para poder realizar una selección y adaptación de las dimensiones e indicadores de la competencia mediática al $2^{\circ}$ ciclo de E.I. y que estas puedan ser trabajadas de forma eficaz, sin dificultades y de forma adecuada, se ha realizado un estudio basado en el desarrollo del niño en la etapa de Educación Infantil, el uso de los medios en el proceso de enseñanza/aprendizaje, así como se han tenido muy en cuenta las característica de la denominada Inteligencia Fílmica en las edades de 3 a 6 años, 
con el fin de entender cómo se deben utilizar las producciones audiovisuales dentro del contexto escolar con estos alumnos y que ayuden a fomentar la competencia mediática. En este sentido, para conocer en profundidad cuáles son las características que presenta el niño hemos tomado como referencia los siguientes estudios: Busemann (1985); Katz, Busemann, Piaget \& Inhelder (1985); Palacios y Mora (1999); Rodríguez (2000); Berk (2001); De Andrés Tripero (2006); Rafael (2009); Gaitán (2010); Lachat (2011) y Pavez (2012).

Ha sido necesaria una revisión exhaustiva de la literatura más relevante en pos de lograr una adaptación pormenorizada y adecuada de los indicadores de la competencia mediática a esta etapa: Ferrés (2007); Zachetti y Vardakas (2008); Celot \& Pérez-Tornero (2009); Di Croce (2009); Aparici, Campuzano, Ferrés \& Matilla (2010); Bernabeu, Esteban, Gallego \& Rosales, 2011; Pérez-Rodríguez \& Delgado-Ponce (2012); Ferrés \& Piscitelli (2012); Pérez-Tornero \& Pi (2014); García-Ruíz, Duarte \& Guerra (2014); Pérez-Rodríguez, Ramírez \& García-Ruiz (2015). Estas investigaciones han ayudado a sentar las bases de la competencia mediática, el concepto, sus dimensiones e indicadores y han aportado una visión actualizada de los niveles de competencia en la ciudadanía española para trazar los ámbitos de actuación en alfabetización mediática e incidiendo en las políticas educativas.

Se han conservado las 6 dimensiones contempladas en los primeros estudios desarrollados sobre la competencia mediática: Lenguajes, Tecnología, Recepción e interacción, Producción y difusión, Ideología y valores y Estética (Aparici, Campuzano, Ferrés \& Matilla, 2010; Ferrés \& Piscitelli, 2012). Sin embargo, algunos indicadores han sido susceptibles de sufrir alguna modificación y otros directamente han tenido que ser suprimidos por ser inviable su trabajo en los niveles educativos a los que va dirigido este estudio. Los autores contemplan la competencia mediática como la suma de las 6 dimensiones que vienen definidas por una serie de indicadores divididos en dos ámbitos: el del análisis con 37 indicadores y el de la expresión con 22 indicadores. Para hacer más efectivo su estudio y posterior manejo, se le ha asignado a cada indicador una nomenclatura que atiende a la inicial de la dimensión ( $\mathrm{L}=$ Lenguaje; $\mathrm{T}=$ Tecnología; $\mathrm{R}=$ Recepción e interacción; $\mathrm{P}=$ Producción y difusión; $\mathrm{I}=$ Ideología y valores; $\mathrm{E}=$ Estética), seguida de la inicial del ámbito al que pertenece $(\mathrm{A}=$ Ámbito del análisis; $\mathrm{E}=$ Ámbito de la expresión) y el número de orden de la clasificación general y que indicamos en superíndice. De esta forma, articulamos una nueva clasificación más limitada donde se desarrolla la descripción de los indicadores que se pueden considerar idóneos para ser trabaja- dos en el $2^{\circ}$ ciclo de E.I. de forma progresiva, con el fin de que el niño vaya adquiriendo los conocimientos necesarios para alcanzar en su futuro próximo la denominada competencia mediática.

\section{RESULTADOS: ADAPTACIÓN DE LAS DIMENSIONES DE LA COMPETENCIA MEDIÁTICA AL 2 CICLO DE LA EDUCACIÓN INFANTIL}

La alfabetización mediática se fundamenta en unas dimensiones que comportan una serie de indicadores que atienden a conocimientos, destrezas y actitudes de la denominada competencia mediática: lenguajes, tecnología, procesos de recepción y de interacción, procesos de producción y difusión, ideología y valores, estética (Aparici, Campuzano, Ferrés, Matilla, 2010; Ferrés \& Piscitelli, 2012). Se plantea bajo la premisa de que los indicadores sean generales y no pensados para una edad concreta, lo que implica que deban ser adaptados a cada edad, nivel educativo e incluso cultura. De este modo, en el caso que nos ocupa, los docentes deberían ser dominadores de las 6 dimensiones mientras que los alumnos de E.I. estarían en el primer estadio de la adquisición de algunas de las capacidades que conforman a la competencia mediática. De ahí que, en el ámbito educativo, se deba atender a una educación mediática progresiva, que vaya sumando capacidades, habilidades o destrezas conforme el niño va creciendo. Ante la diversidad de estudios, seguiremos la relación de dimensiones e indicadores sobre alfabetización mediática publicada por Ferrés \& Piscitelli (2012) que constituye una ampliación y revisión del estudio de Ferrés (2007), donde introduce aspectos relacionados con la regulación de los medios y la participación ciudadana, sin perder de vista las emociones que suscitan los mensajes de los medios, que eran algunas de las carencias que presentaba su anterior estudio y que fueron puestas de manifiesto por las autoras Pérez y Delgado (2012). En este sentido, consideramos necesario una selección y adaptación de las mismas para que puedan ser trabajadas y faciliten su inclusión al profesorado en los niveles que engloban el Segundo ciclo de la E.I. Algunos indicadores serán descartados de la clasificación original y otros serán matizados con el fin de ser adaptados a las edades de entre 3 a 6 años.

1. Lenguajes - A grandes rasgos esta dimensión se centra en los códigos del lenguaje audiovisual, sus reglas, el uso que hacemos para comunicarnos, el análisis de los mensajes, la estructura, la narrativa audiovisual, entre otros. Sin embargo, vamos a tratar de matizar los indicadores que conforman esta dimensión: 
Ámbito del análisis:

LA $^{1}$. Capacidad de interpretar y de valorar los diversos códigos de representación y la función que cumplen en un mensaje: como tal, la interpretación y valoración del uso de los elementos que conforman el lenguaje audiovisual sería complicada de adquirir a estas edades, pero sí que podríamos atender a determinados elementos como la música o la tipología de planos y explicar su elección y significación a lo largo de la trama audiovisual. Para ello, sería viable asociarla a la dimensión de recepción e interacción, concretamente con el indicador $\mathrm{RA}^{3}$ que atiende a las emociones y que bien se pueden trabajar a través de estos códigos audiovisuales.

- LA $^{2}$. Capacidad de analizar y de valorar los mensajes desde la perspectiva del significado y del sentido, de las estructuras narrativas y de las convenciones de género y de formato: $\mathrm{A}$ estas edades el alumno se encuentra en el segundo estadio de la denominada Inteligencia Fílmica de ahí que el niño todavía no entienda bien las estructuras narrativas audiovisuales que se alejan de la estructura clásica lineal (presentación, nudo, desenlace). Los saltos en el tiempo a través de 'flashback' o 'flashforward' son difíciles de captar y pueden provocar un mal entendimiento de la trama o hacer que el niño se pierda en el discurso audiovisual. Pensemos que a estas edades están adquiriendo el sentido del tiempo. Sin embargo, una buena elección del producto audiovisual puede servir al docente para comenzar a trabajar este aspecto y que los saltos en el tiempo, en determinadas producciones, sirvan para distinguir entre el antes y el después de un determinado suceso. Incluso, el paso de los años en los personajes es uno de los aspectos fácilmente apreciables a través de las imágenes. A través de estos ejemplos se podría tener en cuenta esta capacidad en E.I., puesto que dan sentido a lo que acontece a lo largo de la trama narrativa audiovisual.

- LA $^{3}$. Capacidad de comprender el flujo de historias y de informaciones procedentes de múltiples medios, soportes, plataformas y modos de expresión: a estas edades el niño comienza a entender la secuencialidad de las historias (capítulos) y dónde localizarlas, sobre todo si tenemos en cuenta aquellas producciones transmedia con las que poder satisfacer las necesidades del niño.

$L^{4}$. Capacidad de establecer relaciones entre textos -intertextualidad-, códigos y medios, elaborando conocimientos abiertos, sistematizados e interrelacionados: los productos audiovisuales destinados para este público potencial surgen bajo las premisas de la narrativa transmedia. A día de hoy, es fácil que el niño establezca relaciones entre la diversidad de productos que conforman un mismo paquete de productos audiovisuales que giran en torno a un mismo personaje y de sus historias. Pensemos en las músicas de las series infantiles que son comercializadas a través de $\mathrm{CD}$ y que son fácilmente reconocibles por los menores nada más sonar, aunque no tengan delante ninguna imagen visual, sin embargo, el conocimiento de la serie genera en sus mentes ese universo solo con los sonidos. Lo mismo ocurre con los cuentos o los videojuegos a través de los que se puede establecer esa relación.

\section{Ámbito de la expresión:}

$L^{1}$. Capacidad de expresarse mediante una amplia gama de sistemas de representación y de significación: la comunicación no solo se basa en el lenguaje verbal, existen otros sistemas, como el de la imagen, recordemos la frase proverbial: "una imagen vale más que mil palabras". Pues en esta etapa hagamos honor a que el niño está comenzando a dominar la diversidad de lenguajes y debe también ser capaz de comunicarse con ellos. De hecho, en el currículum del $2^{\circ}$ ciclo de Educación Infantil existe el "Área 3. Lenguajes, comunicación y representación" que incluye el lenguaje audiovisual, por formar estos parte de su vida cotidiana.

- $\quad \mathrm{LE}^{2}$. Capacidad de elegir entre distintos sistemas de representación y distintos estilos en función de la situación comunicativa, del tipo de contenido que hay que transmitir y del tipo de interlocutor: a estas edades el niño es capaz de cambiar el registro del lenguaje en función de la situación en la que se encuentre y con quién esté hablando. La narración, la interpretación, la información... son utilizados en medios como la radio o la televisión, cada uno con sus matices, con entonaciones variables, pues no es lo mismo la locución de un partido de fútbol que la locución utilizada en los informativos, o en magazine. Estos nos sirven de ejemplos de esa variabilidad y pueden ser utilizados por los más pequeños, si hacemos el ejercicio de pedirles que narren tras la escucha activa de un partido o un informativo serían capaces de adaptarse a las situaciones, es decir, de ponerle voz a las imágenes de un partido.

$\mathrm{LE}^{3}$. Capacidad de modificar productos existentes, confiriéndoles un nuevo sentido y valor: el niño es capaz de realizar modificaciones si atendemos al lenguaje, siendo capaz de modificar textos narrativos audiovisuales sencillos. Siguiendo con los ejemplos radiofónicos, pensemos que ponemos al niño a 
escuchar un cuento y posteriormente le pedimos que ahora sea él el narrador de la historia y que nos la cuente. Esa historia ya no será la misma y aparecerán nuevos matices, desde que el niño sea capaz de hacerla suya.

2. Tecnología - El funcionamiento y uso de las diversas herramientas tecnológicas que imperan en el ámbito de la comunicación audiovisual y digital es la clave de esta dimensión. Así, para el Segundo ciclo de la E.I. podríamos tener en cuenta los siguientes indicadores:

Ámbito del análisis:

$\mathrm{TA}^{1}$. Comprensión del papel que desempeñan en la sociedad las tecnologías de la información y de la comunicación y de sus posibles efectos: los medios de comunicación forman parte activa de la vida cotidiana del niño, encontrándose estos implantados en los hogares. Desde la escuela el docente puede comenzar a inculcar en los más pequeños este indicador, simplemente planteando un repaso diario o semanal de los usos, momentos, lugares en que vienen siendo utilizadas por los niños. Incluso comenzar a dar pautas genéricas y consejos sobre uso responsable.

- TA $^{2}$. Habilidad para interactuar de manera significativa con medios que permiten expandir las capacidades mentales: la interacción con los medios a estas edades es constante; interactúan con múltiples pantallas (televisión, ordenador, smartphone, tablet, consola...) que permiten llevar a cabo procesos de enseñanza/aprendizaje. Esta interacción debe ir acompañada de la elección de buenos productos acordes a las capacidades cognitivas del niño, que satisfagan sus necesidades de formación y entretenimiento, pero que recae en el educador (docente o padres) y desde la escuela se puede fomentar esta habilidad a través del planteamiento de problemas o actividades que el niño deba resolver a través de diferentes soportes, lo que le va a permitir realizar esa interacción de forma significativa y con un fin.

3. Recepción e interacción - Identificación de las audiencias o valoración de las emociones que transmiten los mensajes de los medios en los procesos de recepción son algunos de los indicadores que definen esta dimensión que se basa en la interacción que realiza el individuo con el medio. Sin embargo, sólo seleccionaremos 4 de las 8 que la conforman:

Ámbito del análisis:

$\mathrm{RA}^{2}$. Capacidad de dilucidar por qué gustan unos medios, unos productos o unos contenidos, por qué tienen éxito, individual o colectivamente: qué necesidades y deseos satisfacen en lo sensorial, en lo emotivo, en lo cognitivo, en lo estético, en lo cultural, etc.: todos estos aspectos relacionados con los gustos y necesidades también pueden ser trabajados en el Segundo ciclo de la E.I. Los niños a estas edades saben qué series de TV les gusta ver o a qué personaje les gustaría parecerse, incluso consideramos que de 3 a 6 años son capaces de dar una explicación al por qué de esos gustos. Por tanto, es factible poder trabajar esta capacidad posteriormente al visionado de una serie de animación infantil, de un corto o de un largometraje, de forma verbal (asamblea de preguntas y respuesta) o incluso a través de actividades más manuales, con el fin de que el niño dé respuesta al por qué de aquello que recepciona, ya no solo en el ámbito escolar sino en el familiar.

- RA ${ }^{3}$. Capacidad de valorar los efectos cognitivos de las emociones: tomar conciencia de las ideas y valores que se asocian con personajes, acciones $y$ situaciones que generan, según los casos, emociones positivas y negativas: los medios audiovisuales son escaparate de historias reales o imaginadas, donde la exposición de los sentimientos y de las emociones son recurso imprescindible para mostrar los estados anímicos de los personajes ante las acciones que se van sucediendo a lo largo de la trama narrativa audiovisual. Esto hace que los receptores sientan más o menos empatía hacia un determinado personaje, ante sus actos y formas de resolver los conflictos. En el Segundo ciclo de la E.I. podemos jugar al reconocimiento de las emociones, pensemos en las series infantiles de animación donde los sentimientos de los personajes son acentuados por la expresividad de los movimientos y sobre todo de los rostros, para que el niño sea capaz de entender lo que le sucede al personaje -si está triste, contento, feliz, enfadado, ...- y esto bien se puede trabajar a través de un análisis de las situaciones. Es decir, reflexionar con el menor sobre lo que ha sucedido $\mathrm{u}$ ocurrido para que el personaje haya reaccionado emocionalmente de una determinada forma, y esto asociarlo a situaciones de la vida cotidiana del niño, con el fin de que el alumno adquiera esta capacidad.

$\mathrm{RA}^{5}$. Conocimiento de la importancia del contexto en los procesos de recepción y de interacción: el contexto a la hora de recepcionar un determinado producto audiovisual puede influir en la manera en la que el niño interactúa con el mismo, en la comprensión del mensaje, en que esté más o menos atento, en que pierda el hilo de la trama, etc. Hoy en día, la posibilidad de contextos desde el que recibir un determinado mensaje puede ser de diversa índo- 
le gracias a la multiplicidad de pantallas existentes. Así, la comunicación multimodal o transmedia ya estudia esta diversidad y la adaptación del producto a las mismas. De ahí que existan medios que propician una recepción individual (ordenador, tablet o smartphone) y otros cuya recepción es propicia para la colectividad (cine o televisión), permitiendo compartir el espacio físico de la recepción (hogar, aula, sala de cine) con el contexto donde se desarrollan las historias en la pantalla, compartir las sensaciones y las emociones al mismo tiempo que el compañero que tenemos sentado al lado o incluso compartir la experiencia del visionado con personas que no conocemos (sala de cine), pero que se convierten en un grupo o unidad a través de la magia del cine al visionar al unísono la narrativa audiovisual. Estos aspectos se pueden comenzar a trabajar con los más pequeños, pensemos por un momento en las normas básicas de comportamiento cuando asistimos a una sala de cine y que permiten convivir con los demás en un mismo espacio y sin conflictos, lo que propicia una buena recepción. Normas que incluso pueden ser extrapolables a los visionados en el aula.

- $\quad \mathbf{R A}^{7}$. Capacidad de apreciar los mensajes provenientes de otras culturas para el diálogo intercultural en un periodo de medios transfronterizos: la tolerancia y el respeto ante las creencias, la solidaridad o la curiosidad por la diversidad cultural son valores que se deben inculcar desde la más tierna infancia. Pondremos el ejemplo de la serie de animación infantil andaluza Andaluna y Samir que trata precisamente de fomentar el diálogo intercultural entre los menores, un recurso audiovisual educativo pensado para trabajar desde las aulas escolares. Por tanto, otra capacidad que el niño de E.I. debería de ir adquiriendo desde el Segundo ciclo a través del uso de los medios de comunicación, ya que el docente no sólo tiene a su alcance series de animación, sino también documentales, cortometrajes, películas... que ponen de manifiesto las características de las diferentes culturas.

4. Producción y difusión - Esta dimensión se escapa a las edades con las que pretendemos trabajar, de 3 a 6 años, ya que sus indicadores son muy específicos -responsables y fases de la producción, aprovechamiento de los recursos tecnológicos, cultura participativa, etc.- y se escaparían al entendimiento del niño, por tener éste una corta edad. No obstante, podríamos adaptar y tener en cuenta las 3 siguientes:

Ámbito del análisis:

$\mathbf{P A}^{1}$. Conocimiento de las diferencias básicas entre las producciones individuales y las colectivas, entre las populares y las corporativas, y, en el ámbito de estas últimas, si es el caso, entre las elaboradas por instancias de titularidad pública y privada: quizás no sea capaz de conocer todos los tipos de producciones, dada la corta edad del niño, pero podríamos comenzar ejercitando la diferencia entre una producción individual y una producción colectiva. Estos aspectos podrían ser trabajados en el $2^{\circ}$ ciclo de E.I. con dos ejemplos muy sencillos: los alumnos de entre 3 a 6 años son capaces de tomar una fotografía por sí solos y una foto (no profesional) bien podría ser considerada una producción individual, ya que no necesitan de otras personas para ser tomada. Sin embargo, si pensamos en otro tipo de productos audiovisuales como series de animación, programas de radio o televisión, películas, retransmisiones deportivas... todos ellos necesitan de un equipo de trabajo (periodistas, guionistas, iluminadores, reporteros gráficos, actores, directores, locutores, productores...), de la colaboración de los unos con los otros, del reparto de tareas para que el producto pueda ser realizado, es lo que denominamos producción colectiva. Por tanto, esta diferenciación básica podría comenzar a trabajarse desde los primeros años de escolarización.

\section{Ámbito de la expresión:}

$\mathrm{PE}^{2}$. Capacidad de trabajar, de manera colaborativa, en la elaboración de productos multimedia o multimodales. El trabajo en equipo y la colaboración en esta etapa educativa es fundamental, la convivencia con el otro, el tomar en cuenta a los demás son aspectos fundamentales para la convivencia y el trabajo en sociedad. Se sabe que los medios se caracterizan por el trabajo en equipo; un programa de radio, de televisión o una película se ponen en marcha porque hay detrás un gran equipo de profesionales, que trabajan al unísono, con la finalidad de crear un determinado producto audiovisual. En el ámbito educativo ocurre lo mismo, se necesita de la colaboración de todos los agentes implicados para sacar adelante proyectos que mejoren los procesos de enseñanza/aprendizaje. Por ello, en el $2^{\circ}$ ciclo de E.I. el niño debe aprender a compartir y a empezar a darse cuenta de que existen procesos en los que se necesita de la colaboración de otros para que funcionen. Podríamos poner como ejemplo, el ejercicio de crear una narración para radio donde cada uno de los niños podría adquirir un rol (personaje) diferente y que su intervención fuese necesaria para el progreso de la historia y el docente sería el encargado de la difusión del mismo a través de un podcast o a través de la radio interescolar. 
- $\quad \mathrm{PE}^{3}$. Capacidad de seleccionar mensajes significativos, apropiarse de ellos y transformarlos para producir nuevos significados. Si pensamos en series de animación o en largometrajes, el niño tiende a quedarse con lo esencial, con aquello que más le ha gustado, con aquello que más ha llamado su atención, con aquella acción que ha realizado el personaje con el que más ha empatizado. Quizás no sea capaz de recordar toda la trama narrativa audiovisual si no conserva una estructura lineal, pero sí es capaz de darle sentido a esas acciones, incluso de recrear nuevas historias y nuevos finales con los personajes. Además, recordemos que está en una fase de la inteligencia fílmica donde impera la imitación, donde reproduce aquello que le muestran las pantallas y son capaces de convertirse rápidamente en la princesa del cuento, en el héroe de la historia, en la bruja malvada, en el pirata, la doctora, el vaquero, etc. Es decir, se apropian de ellos y los trasladan a sus juegos, en definitiva, los transforman para que formen parte de su realidad.

5. Ideología y valores - Vendría a estar definida por indicadores que atienden a la capacidad de lectura comprensiva y crítica, tanto de los mensajes audiovisuales como de los valores que representan esa realidad. Así, de los 11 indicadores que configuran esta dimensión sólo seleccionaremos 4:

Ámbito del análisis:

$I^{1}{ }^{1}$. Capacidad de descubrir la manera como las representaciones mediáticas estructuran nuestra percepción de la realidad, a menudo mediante comunicaciones inadvertidas: pensemos en la publicidad insertada en una determinada serie o película familiar que hacen que de forma subliminal los más pequeños quieran comer un determinado producto, vestir de una determinada marca... igual que el personaje de su serie favorita. La imitación forma parte de esta etapa infantil, se sienten identificados con el personaje, con su forma de actuar y se creen superhéroes, princesas, estrellas del pop, etc., siendo incapaces, a estas edades, de distinguir entre realidad y ficción. Por tanto, el entrenamiento de la percepción de lo real y lo ficcional se presenta imprescindible a estas edades y es necesario ayudar al niño a realizar esta distinción. Ya que la ficción, sobre todo la del género fantástico o de aventuras difiere, en ocasiones, de lo que sucede en el entorno del niño y si no se les advierte pueden extrapolar comportamientos observados en la pantalla a su mundo real donde las normas sociales no las contemplan.
$\mathrm{IA}^{4}$. Capacidad de detectar las intenciones o intereses que subyacen tanto en las producciones corporativas como en las populares, así como su ideología y valores, explícitos o latentes, adoptando una actitud crítica ante ellos: uno de los mensajes que por excelencia se mueve por la intención o el interés es la publicidad. Las promociones y los spots publicitarios plagan las pantallas, incluso están presentes en las parrillas de programación de los Canales Infantiles Politemáticos (Melgarejo y Rodríguez 2011); una publicidad cada vez más especializada que trata de convencer a grandes y a pequeños con el objetivo de vender, creando necesidades. Los menores son más propicios a sentir esta atracción, ya que no son inmunes a las técnicas persuasivas utilizadas por este tipo de género. Por ello, la distinción de las intenciones de los diferentes mensajes audiovisuales que recibe también es importante, por lo menos, en esta etapa, debería adquirir la capacidad de diferenciar entre lo que es publicidad de lo que no es.

- IA $^{6}$. Capacidad de analizar las identidades virtuales individuales y colectivas, y de detectar los estereotipos, sobre todo en cuanto a género, raza, etnia, clase social, religión, cultura, discapacidad, etc., analizando sus causas y consecuencias: a estas edades la diferenciación de los rasgos fundamentales que diferencian al individuo en la sociedad por el género, la raza, la etnia, o la clase social pueden ser trabajadas desde el aula y a través de las producciones audiovisuales. Lo que hará valorar al niño desde pequeño a cada uno por lo que es, sin discriminaciones, valorando y respetando las diferencias culturales a través del trabajo con los estereotipos. Recordemos series de animación infantiles como "Las mil y una américas" o "Andaluna y Samir", que han puesto en valor otras culturas y que nos han dado a conocer la importancia de la identidad y de la procedencia.

IA $^{8}$. Capacidad de reconocer los procesos de identificación emocional con los personajes y las situaciones de las historias como potencial mecanismo de manipulación o como oportunidad para conocernos mejor a nosotros mismos para abrirnos a otras experiencias: las emociones ya han sido trabajadas en el $\mathrm{RA}^{3}$, sin embargo, es un aspecto recurrente en las dimensiones de la Competencia Mediática. Así, se tienen en cuenta los efectos, la identificación y la gestión de las mismas a través de las pantallas. La identificación y la gestión de las emociones es uno de los aspectos que se trabajan en el Segundo ciclo de la E.I. y este indicador bien puede ser trabajado a través de las producciones audiovisuales junto al 
IA $^{9}$. Capacidad de gestionar las propias emociones en la interacción con las pantallas, en función de la ideología y de los valores que se transmiten en ellas. Los mensajes audiovisuales nos suscitan emociones, sensaciones y hasta son capaces de hacernos vivir los sentimientos de un determinado personaje. Las pantallas hacen al niño reír, llorar, entristecerse, alegrarse, asustarse y hasta enfurecerse; sensaciones que el niño tiene que aprender primero a identificar para posteriormente poder dominarlas o más bien gestionarlas. La serie de animación infantil Pocoyó puede ayudar al maestro en esta tarea, ya que el personaje es muy expresivo, tanto en los movimientos como en el rostro, y el niño puede identificar cómo se siente Pocoyó en cada momento. También podemos recordar una de las producciones de Disney Pixar, "Del revés" (2015) donde se pone de manifiesto el funcionamiento, la identificación y la gestión de las emociones en el individuo. Quizás una producción que se escapa al $100 \%$ del entendimiento del niño de 3 a 6 años, sobre todo por su estructura narrativa y la multiplicidad de escenas que se suceden, pero que nos puede ayudar en el trabajo de ir inculcando poco a poco en el alumno este tipo de capacidades.

6. Estética.- Esta dimensión se centra en el sentido de la estética en los mensajes audiovisuales, ya que esta capacidad pretende que el receptor sea capaz de gestar un juicio estético a la hora de valorar un producto primando la manera en que se presentan los mensajes. Además, une el análisis, la valoración y el disfrute de las innovaciones formales y temáticas.

Ámbito del análisis:

EA $^{1}$. Capacidad de extraer placer de los aspectos formales, es decir, no solo de lo que se comunica sino también de la manera como se comunica: el gusto estético dentro de unos cánones de belleza es educable, existen principios que regulan la estética dependiendo de las disciplinas, incluso podríamos matizar que con los años han ido evolucionando (arquitectura, pintura, ilustración, escultura...). En lo audiovisual ocurre algo parecido, pongamos como ejemplo el paso de la estética del blanco y negro al color que aporta nuevas significaciones al mensaje audiovisual. Por tanto, consideramos que se puede introducir esta dimensión en las primeras etapas escolares; pensemos en colores asociados a estados de ánimo, emociones, paisajes lúgubres u oscuros que provocan el miedo en los más pequeños, o aquellos donde impera el colorido y hacen que sea agradable para ellos. Y no olvidemos que no solo podría- mos educar a través de la estética del color, sino también con la de las formas, las tipografías o la de las imágenes.

- EA ${ }^{2}$. Sensibilidad para reconocer una producción mediática que no se adecue a unas exigencias mínimas de calidad estética: si educamos la mirada del niño atendiendo al indicador anterior, irá adquiriendo sensibilidad para reconocer todo aquello que se salga de los cánones estipulados. Pongamos un ejemplo: la estética de los dibujos animados actuales difiere mucho de la de los años 80 y 90 , muchas de las series que en esas épocas fueron un éxito, no han resistido al paso del tiempo y algunas han sido adaptadas a los nuevos tiempos, para hacerlas más atractivas, con un dibujo y color más definido, más parecida a la estética del videojuego que al dibujo clásico, capaz de atraer la atención del menor. En las parrillas de programación - "Heidi" o "La abeja Maya”- y en las nuevas producciones cinematográficas donde se adaptan los clásicos del cine infantil y familiar para hacerlos más realistas: "Cenicienta", "Alicia en el País de las maravillas", "El libro de la Selva", etc.

- $\mathrm{EA}^{3}$. Capacidad de relacionar las producciones mediáticas con otras manifestaciones artísticas, detectando influencias mutuas: encontrar similitudes y asociaciones entre diferentes manifestaciones artísticas se presenta fácil de trabajar en esta etapa. Recordemos aquellas producciones audiovisuales basadas en personajes relevantes de la historia: escritores, pintores, Santos, descubridores... y a través de la que el niño podría encontrar una relación con otras manifestaciones artísticas. Series como "Don Quijote", "Érase una vez..." o "Las mil y una américas" son ejemplo de producciones que nos sirven para trabajar este indicador. No sólo las series infantiles han trabajado este aspecto, existen innumerables largometrajes basados en las vidas y obras de personajes ilustres que del papel han pasado tanto a la pequeña como a la gran pantalla.

\section{Ámbito de la expresión:}

$E^{1}$. Capacidad de producir mensajes elementales que sean comprensibles y que contribuyan a incrementar los niveles personales o colectivos de creatividad, originalidad y sensibilidad: el medio radio nos podría servir para ilustrar este indicador, la producción de mensajes radiofónicos por parte del niño es viable a estas edades. Contar historias, narrar lo que le ha acontecido en el fin de semana o cómo se siente, etc., puede ser un buen modo de trabajar esta capacidad a la vez que se trabaja el lenguaje verbal, 
la oralidad, el orden de la ideas, la elección de las palabras adecuadas para expresar una idea, la dicción, los matices en la entonación cuando se realiza una pregunta o una exclamación, etc.

$\mathrm{EE}^{2}$. Capacidad de apropiarse y de transformar producciones artísticas, potenciando la creatividad, la innovación, la experimentación y la sensibilidad estética: la pintura nos sirve de ejemplo para entender este indicador, ya que el niño es capaz de reproducir una obra y dejar volar su imaginación para transformarla, para hacer uso de las formas y los colores que considere oportunos porque lo que en la obra pictórica es azul, puede que ellos lo interpreten de otro modo, le otorguen otro color y le confiera una nueva significación. De este modo, podemos jugar con la reproducción de los planos de sus series o de sus películas favoritas, que los reproduzcan en el papel dejándoles libertad para que modifiquen e introduzcan elementos, pero sin perder de vista los principios estéticos de la imagen.

La figura 2 representa aquellos indicadores correspondientes a las 6 dimensiones de la competencia mediática en el $2^{\circ}$ ciclo de E.I. Así, como se puede observar, aquellos cuadros iluminados señalan las dimensiones y los indicadores susceptibles de ser trabajados con alumnos de entre 3 a 6 años de edad, mientras aquellos cuadros con trama punteada hacen referencia a aquellos indicadores que bien son alcanzables en otras etapas educativas o serán adquiridos por el individuo en algún momento de su vida, haciendo alusión a la denominada formación permanente, característica de la sociedad del conocimiento. Por tanto, y atendiendo al diseño de la figura, es necesario aclarar que las dimensiones de la competencia mediática no se pueden entender de forma individual sino que están pensadas para ser trabajadas desde la globalidad y de forma progresiva, atendiendo a las características del alumno. De esta forma, no se pierde de vista la propuesta original de dimensiones e indicadores, ya que como indicaban Ferrés \& Piscitelli (2012) "en el lenguaje de la comunicación mediática, el lenguaje, por ejemplo, no puede entenderse sin la tecnología. Del mismo modo, ni la ideología ni la estética pueden entenderse sin el lenguaje” (p. 76). Aspecto éste fundamental si atendemos a la E.I., ya que el trabajo por materias debe hacerse de forma globalizada y transversal, sin atender a las áreas que recoge el currículo de forma individualizada o aislada, sino entendiendo a la E.I. como un proceso de enseñanza/aprendizaje continuo, basado en el juego y en el descubrimiento del que los medios de comunicación también deben formar parte. Por tanto, se hace necesaria la articulación, dentro del

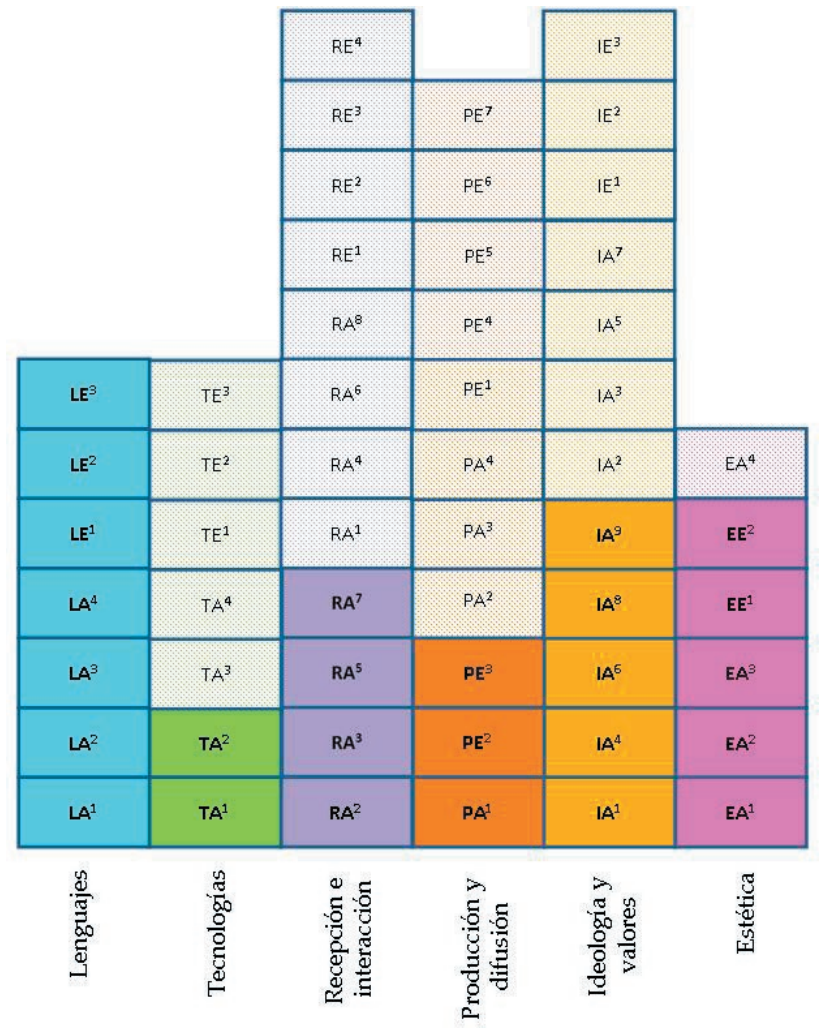

Figura 2. Dimensiones e indicadores de la competencia mediática en el $2^{\circ}$ ciclo de E.I. Fuente: elaboración propia.

ámbito educativo y desde las primeras etapas escolares, de propuestas didácticas innovadoras donde los medios de comunicación dejen de ser entendidos como simples recursos, aspecto éste ya reivindicado por los teóricos que venimos trabajando a lo largo de este estudio.

\section{CONCLUSIONES}

La ejecución de la competencia mediática en E.I. debe atender a una serie de fases progresivas que vayan en consonancia con los distintos niveles educativos, donde no se pierdan de vista los aspectos relacionados con el currículo educativo y donde se tengan en cuenta las diferentes etapas de la inteligencia fílmica. De esta forma, se consigue revisar de forma idónea las dimensiones formuladas por Ferrés \& Piscitelli (2012) - único documento de referencia sobre dimensiones e indicadores de la competencia mediática en el que se basan todos los escritos posteriores sobre esta temática-, reformularlas y crear un nuevo listado para el $2^{\circ}$ ciclo de E.I. que permite a los docentes introducir la competencia mediática en las aulas de una forma más ágil y eficaz. Solo 26 indicadores de los 55 planteados por Ferrés \& Piscitelli (2012), 
correspondientes a las dimensiones que conforman la competencia mediática, son aptos para ser trabajados en este ciclo, mientras que el resto de indicadores (29) serán adquiridos por el individuo en otras etapas de su vida.

Esta adaptación permitiría que los más pequeños comiencen a evaluar la información, sus significados y el cómo utilizar cada medio y sus mensajes en la satisfacción de sus propias necesidades y de las del entorno que les rodea. En este sentido, tras la descripción particular de los indicadores que conforman las dimensiones de la competencia mediática, hemos llegado a la conclusión de que existen indicadores fácilmente adaptables a las edades tempranas como aquellos que pertenecen a las dimensiones del Lenguaje o de la Estética. No obstante, encontramos otros que necesitan de una reflexión mayor para poder ser implementados con niños de 3 a 6 años de edad. Pensemos en las dificultades que presenta conseguir que un niño de este grupo etario pueda alcanzar algunas de las habilidades o capacidades que exigen la dimensión Tecnológica o la de Producción y Difusión.

Con la matización de los indicadores en base al $2^{\circ}$ ciclo de E.I. conseguimos que la inclusión de la competencia mediática en las aulas resulte más sencilla, ya que facilitamos al maestro la elección correcta de los indicadores que consideramos idóneos para ser trabajados en este ciclo. Consideramos que si desde los inicios del planteamiento de las dimensiones se hubiesen matizado o seleccionado los indicadores, atendiendo a los diferentes niveles educativos, quizás la implementación en las aulas de la competencia mediática podría ser más sencilla, ya que se le allana el camino al maestro y se le puede mostrar qué indicadores son factibles de ser trabajados en cada etapa.

\section{REFERENCIAS}

AIMC (Ed.) (2018). Más del 40\% de los niños ve contenidos televisivos en los dispositivos móviles o el ordenador. Asociación para la Investigación de los Medios de Comunicación. https://bit.ly/2U64s3x

AIMC (Ed.) (2019). Marco General de los Medios en España 2019. Asociación para la Investigación de los Medios de Comunicación. https://bit.ly/2U5d36q

Aparici, A., Campuzano, A., Ferrés, J., \& Matilla, A. (2010). La educación mediática en la escuela 2.0. https://goo.gl/oMVqbZ

Berk, LE (2001). Desarrollo del niño y del adolescente. Pearson Educación.

Bernabeu, N., Esteban, N., Gallego, L., \& Rosales, A. (2011). Alfabetización mediática y competencias básicas. Proyecto Mediascopio Prensa. La lectura de la prensa escrita en el aula. Madrid, España: Mediascopio. https://goo.gl/k2XO0n

Busemann, A. (1985). Psicología de la segunda infancia y de la edad juvenil. En D. Katz., A. Busemann., J. Piaget., B. Inhelder. Psicología de las edades. Del nacer al morir, 83-121. Morata.

Celot, P., \& Pérez-Tornero, J.M. (2009). Study on Assessmente Criteria for Media Literacy Levels. A comprehensive view of the concept of media literacy and an Understanding of how media literacy level in Europe Should Be Assessed. European Commision.

De Andrés, T. (2006). El desarrollo de la inteligencia fílmica. La comprensión audiovisual y su evolución en la infancia y adolescencia. CNICE.

Di Croce, D. (2009). Media Literacy. Teacher Resource Guide. Canadian Broadcasting Corporation.

Eleá, I. (Ed.). (2014). Agentes e Vozes. Um panorama da mídia-educação no Brasil, Portugal e Espanha. Nordicom.

Erstad, O., Miño, R., \& Rivera-Vargas, P. (2021). Educational practices to transform and connect schools and communities. [Prácticas educativas para transformar y conectar escuelas y comunidades]. Comunicar, 66, 9-20. https://doi.org/10.3916/C66-2021-01

Ferrés, J. (2007). La competencia en comunicación audiovisual: propuesta articulada de dimensiones e indicadores. Quaderns del CAC, (29), 9-17.

Ferrés, J., \& Piscitelli, A. (2012). La competencia mediática: propuesta articulada de dimensiones e indicadores. Comunicar, 19(38), 75-82.

Gaitán, L. (2010). Ser niño en el siglo XXI. Cuadernos de pedagogía, (407), 12-16.

García-Ruíz, R., Duarte, A., \& Guerra, S. (2014). Propuesta de un instrumento de evaluación para medir el grado de competencia mediática en la etapa de educación infantil. Pixel-bit. Comunicación, Lenguaje y Educación, 44(44), 81-96. https://doi.org/10.12795/ pixelbit.2014.i44.06

Gozálvez, V. (2012). Ciudadanía mediática. Una mirada educativa. Dykinson.

Jiménez-Morales, M., Montaña, M., \& Medina-Bravo, P. (2020). Childhood use of mobile devices: Influence of mothers' socio-educational level. Comunicar, 64, 21-28. https://doi.org/10.3916/C64-2020-02

Katz, D., Busemann, A., Piaget, J., \& Inhelder, B. (1985), [1960]. Psicología de las edades. Del nacer al morir. Morata.

Kotilainen, S., \& Kupiainen, R. (2015). Reflections on media education futures. Nordicom: University of Gothenburg.

Lachat, C. (2011). Didáctica de la traducción audiovisual: enseñar a mirar. Redit, (6), 94-105. 
Melgarejo Moreno, I., \& Rodríguez Rosell, M.M. (2011). Los canales infantiles politemáticos de televisión digital en España: análisis y clasificación. Doxa Comunicación. 13. Doi. https://doi.org/10.31921/doxacom. n13a7

Palacios, J., \& Mora, J. (1999). Crecimiento físico y desarrollo psicomotor hasta los 2 años. En J. Palacios., A. Marchesi., y E. Coll. Desarrollo psicológico y educación. 1. Psicología evolutiva (págs. 81-102). Alianza.

Pavez, I. (2012). Sociología de la Infancia: las niñas y los niños como actores sociales. Revista de Sociología, (7), 81-102.

Pérez-Rodríguez, A., \& Delgado-Ponce, A. (2012). From digital and audiovisual competence to media competence: Dimensions and indicators. Comunicar, 39, 25-34. https://doi.org/10.3916/C39-2012-02-02

Pérez-Rodríguez, MA, Ramírez, A., \& García-Ruiz, R. (2015). La competencia mediática en Educación Infantil. Análisis del nivel de desarrollo en España. Universitas Psychologica. 2(14) 619-630. https://goo. $\mathrm{gl} / \mathrm{I} 3 \mathrm{PNZR}$

Pérez-Tornero, J.M., \& Pi, M. (2014). La educación en medios en una España en crisis. En I. Eleá. Agentes e vozes. Um panorama da mídia-educaçao no Brasil, Portugal e Espanha, 247-256). Nordicom.

Rafael, A. (2009). Desarrollo cognitivo: las teorías de Piaget $y$ de Vygostky. Colegio Oficial de Psicólogos de Cataluña. AUB (Universidad Autónoma de Barcelona). https://goo.gl/FKq49n

Rodríguez, I. (2000). ¿Sociología de la infancia? Aproximaciones a un campo de estudio difuso. Revista Internacional de Sociología (RIS). Tercera Época, (26). 99-124. https://goo.gl/H9Ndec

Zacchetti, M., \& Vardakas, P. (2008). A European approach to media literacy. In U. Carlsson, S. Tayie, G. Jacquinot-Delaunay, \& J. M. Pérez Tornero (Eds.), Empowerment through media education: an intercultural dialogue, 117-123. Nordicom, Göteborgs universitet. 